\title{
La vida como radioteatro: estrategias metaficcionales en La tía Julia y el escribidor, de Mario Vargas Llosa
}

\section{Life as Radio-Theater: Metafictional Strategies in Mario Vargas Llosa's Aunt Julia and the Scriptwriter}

\author{
José Carlos Cabrejo \\ Universidad de Lima
}

\section{RESUIMEN}

La tía Julia y el escribidor, novela de Mario Vargas Llosa, es una obra emblemática de la llamada metaficción, aquella ficción que, a grandes rasgos, trata sobre la propia ficción, que reflexiona sobre sus convenciones y sus modos de construcción, y juega con ellos. Este análisis se plantea como objetivo abordar las estrategias metaficcionales que articulan esta novela, a partir de la semiótica en sus vertientes generativa y tensiva.

Palabras clave:

Mario Vargas Llosa / Metaficción / La tía Julia y el escribidor / Semiótica

\section{ABSTRACT}

Aunt Julia and the scriptwriter, novel written by Mario Vargas Llosa, is an emblematic work of metafiction, a type of fiction generally related to the fiction itself that reflects on its conventions and its construction modes, and plays with them. This analysis aims to address the metafictional strategies that articulate this novel, based on generative and tensive semiotics.

\section{Keywords:}

Mario Vargas Llosa / Metafiction / Aunt Julia and the scriptwriter / Semiotics
$\mathrm{P}$ ersonajes que sienten la vida como una ficción, géneros literarios con convenciones que terminan siendo dinamitadas por una narración que se burla de ellas, relatos que cobran una "conciencia" lúdica de su propia escritura. Esos son solo algunos de los rasgos de lo que muchos teóricos denominan como metaficción. Esta expresión es definida por Patricia Waugh de la siguiente manera:
Término que se refiere a aquella escritura ficcional que de forma sistemática y autoconsciente pone atención en su status de artefacto, con el objetivo de hacerse preguntas sobre la relación que existe entre la ficción y la realidad. Al proveer una crítica de sus propios procedimientos de construcción, no solo examina las estructuras básicas de la narrativa de ficción, sino que también explora la posible ficcionalidad del mundo más allá del texto literario. (2003, p. 2)

Según Lauro Zavala, las distintas maneras en que los autores entienden la metaficción se resumen en la siguiente definición:

escritura narrativa cuyo interés central consiste en poner en evidencia, de

1 "Metafiction is a term given to fictional writing which self-consciously and systematically draws attention to its status as an artefact in order to pose questions about the relationship between fiction and reality. In providing a critique of their own methods of construction, such writings not only examine the fundamental structures of narrative fiction, they also explore the possible fictionality of the world outside the literary fictional text". 
manera lúdica, las convenciones del lenguaje y la literatura. (2007, p. 203)

La tía Julia y el escribidor de Mario Vargas Llosa es una novela que cuenta la relación amorosa de un aprendiz de escritor, llamado Varguitas, con Julia, su tía política, mucho mayor que él. Este romance lo enfrenta a su familia. Dicha historia se intercala con capítulos que presentan los radioteatros escritos por un personaje llamado Pedro Camacho, hombre de comportamiento estrafalario que trabaja en la misma emisora donde también lo hace el protagonista. Los capítulos impares corresponden a la aventura melodramática con Julia, y los pares a los radioteatros, a excepción del capítulo XX, que "es como un epílogo a la primera serie de episodios" (Oviedo, 1983, p. 210).

En la referida obra de Vargas Llosa encontramos un caso emblemático de la metaficción, por su aplicación de estrategias vertidas en la tipología planteada por Lauro Zavala (2007, p. 196) en su libro Ironías de la ficción y la metaficción en cine y literatura. Las estrategias metaficcionales que se encuentran en La tía Julia y el escribidor son la construcción en abismo, la parodia de género extraliterario, la tematización del lector y la metalepsis. El presente artículo, en ese sentido, apunta a explorar cómo es que dichas estrategias conforman la novela del autor peruano, empleando como base metodológica la semiótica generativa de Algirdas Julien Greimas y la semiótica tensiva de Jacques Fontanille.

En cuanto a la construcción en abismo, André Gide fue el primero en hablar de una mise en abîme, de una narración que alude a la misma narración (Zavala, 2007, p. 343). En La tía Julia y el escribidor, hallamos una escritura que justamente trata sobre la propia escritura, y que se refiere específicamente a la pasión de escribir, que se refleja en dos personajes centrales de la novela: Varguitas, quien no cesa de crear cuentos a lo largo de la obra, y Pedro Camacho, quien, de forma maquinal y veloz, redacta libretos para numerosos y populares radioteatros.
Desde el epígrafe (extraído de El grafógrafo de Salvador Elizondo), que antecede al primer capítulo de la obra, notamos lo que será uno de los grandes temas de esta obra:

Escribo. Escribo que escribo. Mentalmente me veo escribir que escribo y también puedo verme que escribo. Me recuerdo escribiendo ya y también viéndome que escribía. Y me veo recordando que me veo escribir y me recuerdo viéndome recordar que escribía y escribo viéndome escribir que recuerdo haberme visto escribir que me veía escribir que recordaba haberme visto escribir que escribía y que escribía que escribo que escribía. También puedo imaginarme escribiendo que ya había escrito que me imaginaría escribiendo que había escrito que me imaginaba escribiendo que me veo escribir que escribo. (Elizondo, citado por Vargas Llosa, 2008, p. 11)

En el epígrafe se anuncia que la escritura será uno de los temas centrales de la novela. Varguitas es presentado en la obra como un personaje que quiere vivir de la literatura, como, por ejemplo, cuando refiere que fue contratado en la radio por haber publicado un relato por medio de un diario local: "la condición intelectual que me había conferido desde que vio un cuento mío en el suplemento dominical de $E I$ Comercio" (2008, p. 17). 0 cuando, en medio de la narración sobre su aventura romántica con la tía Julia, recuerda cuentos que escribe 0 imagina:

Iba a titular mi cuento "El salto cualitativo" y quería que fuese frío, intelectual, condensado e irónico como un cuento de Borges. (2008, pp. 63-64)

El cuento iba a terminar así, de manera efectista, con el rugido y la palabrota de Jesús. Quería que fuera un cuento cómico y, para aprender las técnicas del humor, leía en los colectivos, expresos y en la cama antes de caer dormido a todos a los escritores risueños que se ponían a mi alcance, desde Mark Twain y Bernard Shaw hasta
Jardiel Poncela y Fernández Flórez. (2008, p. 129)

Otros personajes, como Javier, detectan la importancia que para Varguitas tiene la escritura, al comentarle la posibilidad del suicidio ante los problemas familiares generados por su romance con la tía Julia:

-Si te matas, las porquerías que has escrito se volverán interesantes, la gente morbosa querrá leerlas y será fácil publicarlas en un libro - me convencía, a la vez que se secaba con furia- Te volverás, aunque sea póstumamente, en escritor. (2008, p. 360)

Lo mismo hace la tía Julia cuando le comenta la posibilidad de que llegue su padre para romper su controvertido romance: "Te has puesto pálido, Varguitas. Ahora sí que tienes tema para un buen cuento" (2008, p. 302).

En el último capítulo, que narra su ruptura matrimonial con la tía Julia y su nueva relación con Patricia, su prima, Varguitas sigue imaginando sobre qué escribir, como, por ejemplo, en el siguiente fragmento, en el que hace un guiño a la creación de Conversación en La Catedral, la célebre novela escrita por el autor, Mario Vargas Llosa: cara de la ciudad, bajaba por la avenida Abancay en dirección al Parque Universitario y a lo que había sido antes la Universidad de San Marcos (las facultades se habían mudado a las afueras de Lima y en ese caserón donde yo estudié Letras y Derecho funcionaban ahora un museo y oficinas). No sólo lo hacía por curiosidad y cierta nostalgia, sino también por interés literario, pues en la novela que trabajaba algunos episodios ocurrían en el Parque Universitario, en la casona de San Marcos y en las librerías de viejo, los billares y los tiznados cafecitos de los alrededores. (2008, pp. 473-474).

La construcción metaficcional del personaje de Varguitas no solo consiste en su condición de sujeto en vías de convertirse en (reconocido) escritor. 
También se enraíza en el hecho de reconocerse como creador de ficciones a través de otras ficciones. Explica las características de sus posibles cuentos, refiriéndose a otros escritores 0 a libros que el propio autor de la novela que analizamos llegó a escribir. El protagonista y narrador, aparte de su fijación amorosa con la tía Julia, está obsesionado con escribir: se piensa, se sueña y se imagina escribiendo, como el sujeto del epígrafe de Salvador Elizondo. Los personajes que lo rodean, como Javier o Julia, también lo perciben como un ser abrazado por la ilusión de ser literato.

Por eso mismo, hay una relación especular entre Varguitas y Pedro Camacho. De la misma forma que quienes rodean a Varguitas lo ven sumergido en la escritura, el protagonista ve a Pedro Camacho como un sujeto apasionado por crear con palabras. También se sirve de la ficción para describir las obsesiones creativas de Camacho, como cuando Varguitas refiere, en un capítulo, que el libretista tiene un "atuendo de poeta decimonónico", o compara el estilo de realización de libretos del boliviano con la escritura automática de los surrealistas: "una vez le dije que verlo trabajar me recordaba la teoría de los surrealistas franceses sobre la escritura automática, aquella que mana directamente del subconsciente, esquivando las censuras de la razón" (2008, p. 171).

No obstante, en el modo de creación que presentan Varguitas y Pedro Camacho, está la oposición entre ambos. A través de la semiótica tensiva, el tempo, "dicho de otro modo, la velocidad" (Zilberberg, 2006, p. 475), es un concepto que nos puede servir para explicar dicha contrariedad. Si lo que caracteriza a Varguitas es la lentitud para ordenar las ideas que le servirán para sus escritos, lo que perfila a Camacho es su rapidez, lo que se constata en un fragmento de la novela como el siguiente, que describe cómo el protagonista observa al libretista tecleando en su máquina de escribir:

Divisé mi Remington. La sentí funcionando, oí el sonido de sus gordas teclas contra el rodillo, pero no vi a nadie detrás de ella. Metí la cabeza por la ventana y el mecanógrafo era Pedro Camacho [...], de modo que escribía con las manos al nivel de los ojos y daba la impresión de estar boxeando... Tenía los desorbitados ojos fijos en el papel, tecleaba con dos dedos, se mordía la lengua. (2008, p. 59)
Varguitas describe los movimientos escriturales de Camacho como un fenómeno de rapidez boxística. Por ello, Anke Birkenmaier apunta que las velocidades distintas que muestran en su escribir ambos personajes tienen que ver con ópticas distintas de creación, una culta y otra industrial:

Esta asociación entre la escritura automática de los surrealistas y la de los radionovelistas viene de un escritor joven y ambicioso, resentido del público cada vez más amplio de la radio. Le opone a la radionovela su erudición — se presenta como alguien que conoce el surrealismo francés muy bien-y su escritura artesanal, más lenta que la producción en cantidades industriales del escriba. (2008, p. 685)

Volviendo al asunto tensivo, la escritura de Varguitas está dotada de un tempo lento, que requiere de una mayor extensión temporal, de más duración para desarrollarse; en cambio, la escritura de Pedro Camacho se caracteriza por un tempo rápido, que, por el contrario, implica una menor extensión temporal, una brevedad en su concreción, tal como se puede apreciar en los siguientes esquemas:

\section{Escritura de Varguitas}

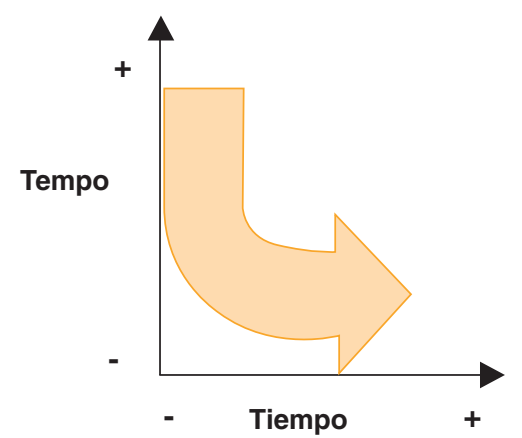

Escritura de Pedro Camacho

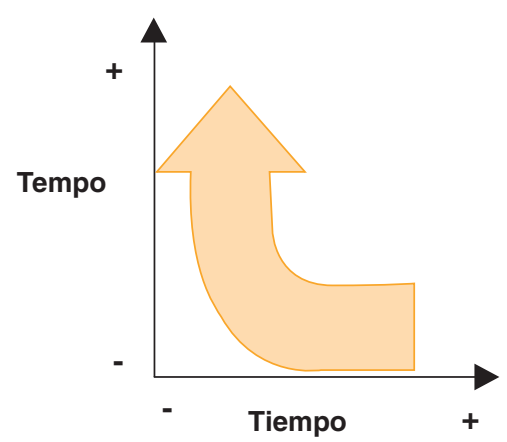


Parafraseando lo antes dicho, como bien lo indican las flechas gruesas que están al interior de los esquemas, en el caso de Varguitas estamos ante una escritura que tiende hacia un tempo lento, menor (-) y, por lo tanto, a una duración o tiempo mayor (+); mientras que en el caso de Pedro Camacho identificamos una escritura que se orienta a un tempo veloz, máximo (+), $y$, en ese sentido, a una abreviación, un tiempo menor (-).

Esas correlaciones opuestas entre tempo y tiempo terminan reflejando aquella distinción que hace Roland Barthes de los términos de écrivain (escritor) y écrivant (escribiente), que, a continuación, comenta José Miguel Oviedo: "El 'escritor' [...] emplea la palabra escrita no como medio sino como fin. [...] Por otra parte, los "escribientes" son hombres "transitivos", que emplean las palabras como instrumentos" (Oviedo, 1983, p. 216).

En otras palabras, Varguitas, como "escritor", tiene a la palabra como un objeto de valor final a obtener, mientra que Pedro Escribano, como "escribiente", usa la palabra como medio u objeto de valor modal para capturar la atención de un numeroso público radioescucha.

Por eso mismo, Liliana Tiffert Wendorff señala que:

Los radioteatros, además de construir el meollo temático de la obra, aleccionan, añaden humor y entretienen. Sirven además para contrastar y cuestionar dos posturas literarias consideradas antagónicas, si bien, paradójicamente, son complementarias: la función del escritor vs la del 'escribidor' y, por consiguiente, la de lo literario vs lo popular. (2006, p. 25)

Camacho, quien trabaja en función de los ajustados tiempos comerciales de la radio, es un "escribiente", o, en todo caso, y lo que sería lo mismo (como lo dice el título de la novela), un "escribidor". Él, aun así, no deja de evocar otros rasgos que son propios del "escritor", como en aquel pasaje de la novela en que se disfraza, se "traviste", para crear sus historias:
Fue hasta la maleta, la abrió, y empezó a sacar de sus entrañas, como el prestidigitador saca palomas 0 banderas del sombrero de copa, una inesperada colección de objetos: una peluca de magistrado inglés, bigotes postizos de distintos tamaños, un casco de bombero, una insignia de militar, caretas de mujer gorda, de anciano, de niño estúpido, la varita del policía de tránsito, la gorra y la pipa de lobo de mar, mandil blanco del médico, narices falsas, orejas postizas, barbas de algodón... Como una figurita eléctrica, mostraba los artefactados y, ¿para que los apreciáramos mejor, por una necesidad íntima?, se los iba enfundando, acomodando, quitando, con una agilidad que delataba una persistente costumbre, un asiduo manejo... Al mismo tiempo que operaba estas mudanzas, iba hablando, lleno de ardor:

- ¿Por qué no voy a tener derecho, para consubstanciarme con personajes de mi propiedad, a parecerme a ellos? ¿Quién me prohíbe tener, mientras los escribo, sus narices, sus pelos y sus levitas? (2008, p. 177)

Camacho es "escribiente", pero, a la vez, representación figurada de un "escritor", aquel que disfraza la realidad para dar vida a un artificio, como bien apunta Tamayo Vargas:

Para darles 'realidad' a sus comparsas, el autor-guionista-locutor -director se disfraza al escribir, ofreciéndonos los dos aspectos de la realización literaria, la toma de los elementos reales de cada personaje, pero a la vez el disimulo, el artificio que significa el arte literario [...]. (1977, p. 137)

En ese sentido, Pedro Camacho, como encarnación de la realización literaria, también es el reflejo de una operación semiótica, aquella en la cual la significación se aleja de referente —el conjunto de "objetos del mundo 'real' que son designados por las palabras de las lenguas naturales" (Quezada, 1992, p. 24) - para devenir así, en palabras de Barthes, en una ilusión referencial, 0 , para decirlo de otro modo, en un "efecto de sentido 'realidad' 0 “verdad”' (Quezada, 1992, p. 26). El "escribiente" radial pretende alejarse de sí mismo, de su identidad, para crear figurativamente la simulación de ser "otro", alguno de los personajes que crea. Al fin y al cabo, es un espejo que también hace ver cómo Varguitas es el "otro" que asimila en el texto las experiencias vividas por el autor, Mario Vargas Llosa, y las transforma en artificio semiótico. La representación del "escritor" y del "escribiente" en la novela desemboca sutilmente en una construcción en abismo. Los disfraces que usa Camacho para convertirse en uno de sus personajes generan la misma ilusión referencial producida por Varguitas, quien aparenta ser la versión "real" o "verdadera" de Mario Vargas Llosa, cuando dicho personaje no es más que su máscara literaria, que mezcla la descripción de hechos que pueden haber ocurrido o no en la vida del autor.

\section{Parodia de género extraliterario}

Diversos autores han definido la parodia de muchas maneras a lo largo de la historia. Para Linda Hutcheon es la "imitación irónica de un modelo 0 referente estilístico o genérico" (citada por Zavala, 2007, p. 332). Según Margaret $A$. Rose es el "refuncionamiento cómico de material lingüístico 0 artístico preconstituido" (citada por Tiffert Wendorff, 2006, p. 40).

La tía Julia y el escribidor, de manera más evidente, funciona como una parodia de un género extraliterario como es el de las radionovelas. Tanto estos relatos como "las fotonovelas, las historias cómicas ilustradas y las telenovelas (...) se derivan del folletín, género no sancionado por el canon, al que además se ha denominado con los términos de novela de folletín, novela por entregas y novela popular" (Jorge B. Rivera, citado por Tiffert Wendorff, 2006, p. 73).

Tiffert Wendorff se refiere a lo vertido en el libro El folletín y la novela popular de Jorge B. Rivera, para mencionar aquellos rasgos del folletín que, según ella, son justamente propios de las radionovelas: 
La estructura del folletín fue, desde su inicio, la de una novela publicada por partes en diarios que se vendían a precios bajos. Se trataba de una literatura popular no legitimada por los académicos sino por el juego del mercado, y en este sentido se diferenciaba de la literatura culta. Los críticos señalan que por lo general toda literatura popular, incluyendo la actual, comparte las características básicas del folletín, cuya estructura interna, de tipo esquemático, se basa, en un conflicto de relaciones interpersonales entre un 'héroe' y un 'villano' que tratan de perjudicarlo, o que a veces usurpa los derechos de una tercera persona, provocando que el héroe luche para reivindicar a la víctima $[\ldots]$

El conflicto sustancial del relato folletinesco se ofrece como un dualismo arquetípico que postula la confrontación de dos mundos: el ideal, en el que reina la bondad, la moral y la justicia, en oposición a otro mundo carente de valores morales... Cada capítulo o entrega de este género popular termina con un corte abrupto de la acción en un momento generalmente crucial, para obligar al lector a comprar el siguiente número. (2006, pp. 75-76)

Dicha autora agrega también que los finales de los folletines se caracterizaban por plasmar el triunfo del bien sobre el mal (2006, p. 76). Sin embargo, las radionovelas de Pedro Camacho, que se intercalan con los capítulos "autobiográficos" de la novela, subvierten, alteran, pervierten las convenciones folletinescas al ennegrecerlos, convertirlos en relatos de personajes absurdos y envilecidos, de rasgos exagerados, de aura sórdida y comportamiento enajenado: protagonistas envueltos en romances incestuosos, en crímenes pedófilos o negocios sexuales (a pesar de su entrega a la religión), en misiones delirantes como exterminar ratas o torturar niños debido a traumas de infancia, etcétera.

\section{Para José Miguel Oviedo es curioso que}

las fantasías de un guionista de radionovelas no sean verdaderos melodramas, típicas historias sentimentales de amor, sino una especie de 'Grand Guignol' construido por medio de la violenta manifestación de los más nefastos sentimientos del corazón humano, lleno de situaciones pesimistas y espantosas. (Oviedo, 1983, pp. 218-219)

Si bien los capítulos que corresponden a los relatos de Pedro Camacho son, en esencia, inconclusos, por terminar con preguntas que sugieren lo que podría ocurrir con la historia en la siguiente emisión radial, muestran valores opuestos a los que caracterizaban los radioteatros convencionales.

Por el contrario, los capítulos "autobiográficos" de la novela se aproximan más a las convenciones de los radioteatros, con un romance prohibido y censurado por la sociedad, que tiene como protagonistas a Varguitas y a su tía política, muchos años mayor que él; un amor que vence todos los obstáculos de los oponentes (Ios padres de Varguitas), hasta llegar a un matrimonio que pudo durar ocho años, tal como lo señala el último capítulo de la obra.

Los "radioteatros" de La tía Julia y el escribidor se acercan al formato del género radial al que parodian, para después alejarse de él; en cambio, los capítulos "autobiográficos" se alejan del formato de los radioteatros, para, finalmente, acercarse a él. Las creaciones de Pedro Camacho se convierten en insumo de la aventura romántica que emprenden Varguitas y Julia, como se nota en el siguiente fragmento:

En nuestras andanzas nocturnas, la tía Julia me resumía a veces algunos episodios que la habían impresionado y yo le contaba mis conversaciones con el escriba, de modo que, insensiblemente, Pedro Camacho pasó a ser un componente de nuestro romance. (Vargas Llosa, 2008, p. 122)

A pesar de que en varios pasajes de la novela, Varguitas expresa su distancia con el tipo de relatos creados por Camacho, su propia vida, la que narra, se desenvuelve como un melodramático radioteatro. La "realidad" en la que vive el personaje se contamina del caracter pasional de aquellas ficciones sonoras. Por eso mismo, La tía Julia y el escribidor, tal como lo afirma Keith Booker, es una novela posmoderna, porque convierte un fenómeno de la cultura popular, como es el radioteatro, en objeto novelístico:

La tía Julia... es uno de los más claros ejemplos de la manera cómo algunos escritores posmodernos usan el lenguaje y las imágenes de la cultura popular como elemento de la literatura. Esta moda se nota alrededor del mundo [...] pero parece ser especialente pronunciada en Latinoamérica, donde escritores como Carlos Fuentes, Manuel Puig y Guillermo Cabrera Infante (sumados a Vargas Llosa) frecuentemente se apegan a la cultura popular como fuente para sus ficciones. (1994, pp. 54-55) ${ }^{2}$

Hay, pues, especularidad entre las convenciones folletinescas del radioteatro y la narración de la aventura pasional de Varguitas.

\section{Tematización del lector}

Varguitas, a diferencia de Pedro Camacho, explica sus reflexiones sobre lo que desea escribir a partir de su condición de lector amante de la literatura, refiriéndose a numerosos autores.

2 "Aunt Julia is one of the most striking examples of the way so many postmodernist writers use the language and images of pop culture as the stuff of literature. This trend is worldwide ... but it seems especially strong in Latin America, where writers like Carlos Fuentes, Manuel Puig, and Guillermo Cabrera Infante (in addition to Vargas Llosa) often rely heavily on pop culture as a source for their fictions". 
El protagonista le dice a Julia que quiere ser escritor por haber leído a Alejandro Dumas:

Le dije que quería escribir desde que había leído por primera vez a Alejandro Dumas, y que, desde entonces, soñaba con viajar a Francia y vivir en una buhardilla, en el barrio de los artistas, entregado totalmente a la literatura, la cosa más formidable del mundo... Me di cuenta, en un momento, que estaba hablando de manera muy fogosa y le dije que por primera vez le confesaba esas cosas íntimas no a un amigo sino a una mujer. (2008, p. 117)

Pero Varguitas, además, aprecia lo que ocurre a su alrededor y en su mundo personal, expresándose como un culto lector, como las referencias que hace a los surrealistas en una conversación con Camacho, ya citada, 0 ante la tía Julia, para dar su visión de lo que es el amor: "Yo le expliqué que el amor no existía, que era una invención de un italiano llamado Petrarca y de los trovadores provenzales" (2008, p. 25).

Para la semiótica tensiva, la significación surge del cruce entre lo sensible y lo inteligible. A partir de ello, obtenemos los procesos de la mira (que se produce con la intensidad, ligada a lo sensible, que se expresa a través de la tonicidad —el acento- 0 del ya mencionado tempo) y de captación (que nos lleva a la percepción de la extensión — o la cantidad—, vinculada a lo inteligible, que se manifiesta por medio del espacio o del tiempo).

La mira y la captación son desarrolladas por un cuerpo propio, que no se entiende como un cuerpo real, perteneciente a una persona. Es una abstracción que sirve para hacer referencia, como bien lo señala Jacques Fontanille, a la "forma significante de una experiencia sensible de la presencia" (citado por Blanco 2009, p. 17). En el simulacro teórico de la semiótica tensiva, el cuerpo propio reacciona ante una presencia; así, la significación se estudia a partir de esos dos elementos.

Tomando en cuenta el fenómeno de los puntos de vista en el discurso, también es importante entender el cuerpo propioy su relación con una presencia por medio de los llamados actantes posicionales: la fuente, el blanco y el (los) actante(s) de control. Estos actantes son aplicables tanto para la mira y la captación como para la intensidad y la extensión. Es decir, de la misma forma en que hablamos de fuentes y blancos de intensidades y extensiones, podemos referirnos a fuentes y blancos de miras y captaciones.

Los actantes de control, por su parte, lo que hacen es regular las relaciones entre las fuentes y los blancos. En ese sentido, la pasión de Varguitas por la literatura es actante de control, dado que regula las relaciones de intensidad y extensión de la fuente de mira y captación (Varguitas) con su blanco (los personajes que lo rodean). Hay una mira tónica (es decir, acentuada, intensa, enérgica) de Varguitas/fuente hacia blancos como Camacho, al verlo escribir con un tempo acelerado y compararlo con los exponentes surrealistas de la escritura automática; o como la tía Julia, dado que su sueño de ser escritor, a propósito de su primera lectura de Dumas, es verbalizado ante ella de "manera muy fogosa". La literatura da lugar a que Varguitas se compenetre, emocionalmente, con ambos personajes. Por otro lado, la pasión literaria también es actante de control, en tanto influye en la extensión concentrada de su captación hacia Julia y Pedro. Es decir, la mira tónica del protagonista se focaliza en esos dos personajes, debido a que le posibilitan expresar su amor por los libros.

\section{Metalepsis}

Consiste en la "yuxtaposición de universo diegético y del universo metadiegético en el interior de la ficción" (Zavala, 2007, p. 342). Es decir, la metalepsis consiste en cómo pueden coexistir planos de ficción y de qué manera, por ejemplo, un personaje puede saltar de uno a otro. La tía Julia y el escribidor presenta metalepsis cuando los personajes de un radioteatro ingresan a otro, a medida que la locura de Pedro Camacho avanza de manera galopante, hasta el punto de alarmar a sus radioescuchas:
En el capítulo XI, un administrador de la estación de radio le comenta al narrador que Camacho empieza 'a pasar personajes de un radioteatro a otro y a cambiarles los nombres, para confundir a los oyentes... el cura de Mendocita se llama como el testigo de Jehová". En la historia del capítulo XII vemos lo que está sucediendo: en la misma historia, Ezequiel Delfín, vendedor ambulante, se convierte sin razón en Lucho Abril Marroquín, visitador médico y protagonista de las historias del capítulo X. En el capítulo XIV, las confusiones son tremendas e imperdonables: el cura Seferino Huanca (capítulo VI), el doctor Alberto de Quinteros (capítulo II) se convierte repentinamente en el reverendo Padre Quintero..., y el viejo señor del campo, Sebastián Bergua (capítulo XII), se convierte en un predicador evangelista. Más adelante, hay personajes como el teniente Jaime Concha, que se ahoga en un capítulo, a pesar de que 'ya se había muerto en el incendio del Callao' hacía tres días... Los capítulos XIV y XVIII constituyen una prueba patética del caos mental que sufre Camacho: hay momentos sin sentido e ilógicos y confusiones absurdas, a veces en párrafos casi consecutivos, como aquel en el que la tragedia que tiene lugar en el estadio acaba en una plaza de toros.

(Oviedo, 1983, p. 222)

Los capítulos que corresponden a los radioteatros de Pedro Camacho se desarrollan como historias independientes, pero poseen, como ya se señaló antes, un tono, un estilo, una atmósfera en común: personajes estrafalarios, seres retorcidos y decadentes, aventuras tremendistas y grotescas. Además, sus antihéroes, al igual que Camacho, bordean los cincuenta años. Pero, la locura del "escribidor" hace que las historias se crucen, y desencadena que, como si se estuviera ante una versión desopilante de El jardín de los senderos que se bifurcan de Jorge Luis Borges, un personaje pase de un espacio-tiempo a otro, de un plano de ficción radioteatral a otro; migración a través de la cual su identidad muta.

La metalepsis de La tía Julia y el escribidor revela otra lectura metaficcional 
de la propia obra. Ya se mencionó, en otro pasaje de este artículo, que Pedro Camacho, a pesar de su condición de "escribiente" o "escribidor", era la representación figurada de un escritor. Pues bien, así como Varguitas se basa en la literatura para crear literatura, Camacho parte de unos personajes de sus historias para crear otros personajes, que forman parte de historias distintas.

El folletinista alumbra relatos de "subliteratura", pero, a la vez, actúa como una radiografía del trabajo de todo literato: tomar, coger, absorber material literario (suyo 0 ajeno) para reelaborarlo y convertirlo en uno nuevo. Como metáfora de un escritor (en el sentido barthesiano), como personaje que actualiza a un novelista, Camacho se presenta como un reciclador. Recordemos que los contenidos discursivos, con un modo de existencia actualizado, se caracterizan por una mira intensa y una captación reducida (Fontanille, 2001, p. 118): dicho personaje actualiza a un literato porque la narración pone acento, fuerza, intensidad en señalar de qué manera Camacho reinventa material ficcional anterior, apenas captándose en la descripción de su comportamiento su sugerente conexión retórica con el trabajo de creación novelística.

Por eso, Pedro Camacho es un reciclador, como el propio Vargas Llosa, quien, en gesto posmoderno, toma ese "desperdicio" narrativo de las radionovelas para convertirlo en auténtica y pura literatura.

\section{Bibliografía}

BiRKEnMAieR, A. (2008). Transparencia del subconsciente: escritura automática, melodrama y radio en La tía Julia y el escribidor. Revista Iberoamericana, 74(224).

Blanco, D. (2009). Vigencia de la semiótica y otros ensayos. Lima: Fondo Editorial de la Universidad de Lima.

Fontanille, J. (2001). Semiótica del discurso. Lima: Fondo Editorial de la Universidad de Lima.

KeItH BookeR, M. (1994). Vargas Llosa among the postmodernists. Florida: University Press of Florida.

Martín, J. L. (1974). La narrativa de Vargas Llosa. Acercamiento estilístico. Madrid: Gredos.

Oviedo, J. M. (1983). La tía Julia o el autorretrato cifrado. En J. M. Oviedo (ed.), Mario Vargas Llosa: Estudios críticos. Madrid: Alhambra.

Quezada Macchiavello, O. (1992). Semiótica generativa. Bases teóricas. Lima: Universidad de Lima.

Stam, R. (1992). Reflexivity in film and literature: From Don Quixote to Jean-Luc Godard. Nueva York: Columbia University Press.

Tamayo Vargas, A. (1977). La realidad y la falacia en La tía Julia y el escribidor. Boletín de la Academia Peruana de la Lengua, (12).

TifFert WendorfF, L. (2006). Camacho c'est moi: Parodia social y géneros literarios en La tía Julia y el escribidor. Lima: San Marcos.

Vargas LloSA, M. (2008). La tía Julia y el escribidor. Madrid: Punto de Lectura.

Waugh, P. (2003). Metafiction: The Theory and Practice of Self-Conscious Fiction. Nueva York: Routledge.

ZavalA, L. (2007). Ironías de la ficción y la metaficción en cine y literatura. México, D. F.: Universidad Nacional Autónoma de México.

Zilberberg, C. (2006). Semiótica tensiva. Lima: Universidad de Lima. 